University of Nebraska - Lincoln

DigitalCommons@University of Nebraska - Lincoln

To Improve the Academy

Professional and Organizational Development Network in Higher Education

1994

Increasing Sensitivity to Diversity: Empowering Students

Mary Anne Johnston

Follow this and additional works at: https://digitalcommons.unl.edu/podimproveacad

Part of the Higher Education Administration Commons

Johnston, Mary Anne, "Increasing Sensitivity to Diversity: Empowering Students" (1994). To Improve the Academy. 310.

https://digitalcommons.unl.edu/podimproveacad/310

This Article is brought to you for free and open access by the Professional and Organizational Development Network in Higher Education at DigitalCommons@University of Nebraska - Lincoln. It has been accepted for inclusion in To Improve the Academy by an authorized administrator of DigitalCommons@University of Nebraska - Lincoln. 


\section{Increasing Sensitivity to Diversity: Empowering Students}

\section{Mary Anne Johnston}

Yale University School of Medicine

This paper describes a model program for increasing sensitivity to diversity in an academic environment. To improve the learning environment for all students, faculty developers provide educational programs that enhance the faculty's understanding of differences related to gender, race, ethnicity, culture, religion, sexual orientation, and physical abilities. This report highlights the process of working closely with students to design and implement an orientation program for first-year students to increase an awareness of the influence of diversity on their learning and working together.

\section{Introduction}

As faculty developers, we frequently raise issues related to diversity in educational workshops and seminars for faculty and staff (Cooper \& Chattergy, 1993; Wadsworth, 1992; Wunsch \& Chattergy, 1991). In many cases, we design programs to increase the faculty's understanding of differences among student populations so that they may be more sensitive to the needs and concerns of their learners. Differences in gender, race, ethnicity, culture, religion, sexual orientation, and physical abilities may have varying influences on the learning needs, styles, and abilities of students. As faculty become more aware of these differences, they are more likely to appreciate and respect the diversity within the classroom. They may not only 
change their own behaviors in relationship to students but learn to deal effectively with the insensitive and inappropriate behaviors that may be expressed by students and other faculty.

Each educational institution has addressed the area of diversity with policies, guidelines, and programs that are consonant with their own educational mission and organizational structure (Beauvais, 1986; Johnston, 1992; Mao, Bullock, Harway, \& Khalsa, 1988; Thomann, 1989). The Office of Educational Development at Yale University School of Medicine has developed a variety of workshops and seminars for faculty and housestaff at the Medical Center. All of these programs are designed to increase sensitivity to diversity in a medical setting. Faculty and housestaff identify and discuss problems they encounter in working with a diverse population of students, as well as with patients, staff, and other health-care professionals.

\section{Developing Student Programs}

Another approach to increasing sensitivity to diversity is to work directly with students on the issues that most concern them. Students who have an opportunity to bring forward their own issues increase their understanding of the effects that diversity has on learning, teaching, and working together. In addition, they develop a sense of confidence in sharing their beliefs, thoughts, and feelings, not only with their peers, but also with faculty and staff within and outside of the classroom.

In the past few years the Office of Educational Development has worked with students to design educational programs that reflect their own particular needs and concerns. The diversity workshop during orientation was especially noteworthy because students were actively engaged in planning and implementing this activity. Many schools now provide orientation seminars or workshops that encourage students to acknowledge and respect the diversity of the student population in the educational environment. Although the focus may be on increasing students' understanding of one another's differences, these programs often prepare students to handle some of the difficult situations that they might face in a particular learning environment. In 
medical schools these programs are often offered by staff in the Offices of the Dean, Student Affairs, or Minority Affairs.

In the summer of 1993, second-year students at Yale School of Medicine asked to be part of the planning and implementation of the three-hour diversity workshop that has been required for all first-year students for the past six years. Because of their active leadership, students were given an opportunity to create the entire workshop with the support of the Offices of Educational Development, Minority Affairs, and Women in Medicine.

As stated in the written material given to the students (Yale Diversity Workshop Packet, 1993), the purpose of the program was:

to open a dialogue in which issues of diversity and discrimination which affect all of us can be discussed. You and your medical school colleagues will be working closely with one another over the next four years and with the medical community for many years to come. You may be put in critical and stressful situations which will require you to trust each other and rely on one another completely. It is our hope that the discussion today will aid in developing the mutual respect for one another that will carry you through the next four years and throughout the rest of your professional careers. (p. 3)

\section{Format}

The educational program was designed to be highly interactive, maximizing the involvement of all 100 new students. The format consisted of a brief introduction, a description of student support groups, a panel discussion, and a small group discussion.

The introduction by the Medical Student Council President set the tone for engaging students in an informal and open discussion of issues related to differences. She stated that the purpose of the workshop was "to open a dialogue, not to preach, but rather to raise issues we feel are important to be aware of."

Representatives from several student groups shared information about the services their groups provide. Leaders from the Asian Americans in Yale Medicine, the Student National Medical Association, the Lambda Health Alliance, the Committee on the Well-Being of Students, and the Office of Women in Medicine presented an overview of their programs. 
During the panel discussion, members from these same groups read three separate cases of situations in which inappropriate or insensitive behaviors were expressed. Following the reading of each case, students in the audience were asked to respond, answering specific questions that were meant to engage students in dialogue about issues related to diversity. A sample case with questions follows:

In a local restaurant, you overhear someone speaking in an angry, disgusted tone. You turn around and are surprised to find that the comments are coming from your ward-attending physician. He/she doesn't see you. The physician has launched into an argument about deviant homosexuals and you suddenly realize that a fellow classmate's name keeps popping up in the conversation. You think you overhear the attending physician state that he/she is going to "get your classmate" next week in rounds.

What do you do?

Do you:

1. Say nothing and assume your friend can handle him/herself in rounds?

2. Tell your friend about the conversation and warn him/her before rounds?

3. Inform your dean/administrator about the conversation you overheard?

4. Attend rounds yourself and interrupt the behavior if it occurs?

5. Confront the physician in the restaurant or the next day regarding the conversation you overheard?

6. Casually walk by his/her table so that you are seen, but say nothing?

The small group discussions that followed the panel were the highlight of the program. Students were divided into small groups to discuss any issues related to their concerns about diversity. Each group was composed of nine first-year students and two upper-class students who facilitated the discussion for $1 \frac{1 / 2}{2}$ hours. The 22 facilitators had no set agenda, but were prepared during a workshop to promote an interactive session. No faculty participated in the small groups. The 
student facilitators believed that students would feel more comfortable interacting with only their peers in attendance.

\section{Faculty Development Role}

The role of the faculty developer in the project was three-fold. Throughout the planning phase, she enthusiastically supported the students in their effort to design an educational program that addressed their concerns. She asked questions that helped the students to clarify the rationale for this experience and to design a format that was highly interactive. In addition, the faculty developer planned and implemented a one-hour workshop to prepare them to act as facilitators during the small group discussions. Following a brief description of verbal and nonverbal behaviors exhibited by facilitators, she used an interactive format to increase the students' comfort and skills in leading small groups. Among other topics, they discussed how to handle students who might be quiet, loquacious, or antagonistic. To evaluate this program, the faculty developer worked closely with the president of the Medical School Council to develop a questionnaire (see Appendix A) that asked students to assess the effectiveness of the program in meeting their needs.

\section{Results}

Eighty-three percent of the students reported that the sensitivity workshop was effective, very effective, or highly effective. About half of the participants stated that the small group discussion was the best part of the workshop, and half reported that the panel with audience discussion of vignettes was the most significant. It was clear that the vignettes encouraged students to discuss strategies for solving specific problems. Additional comments suggested that the workshop was successful in meeting stated objectives: "I liked best the exposure to things I had not thought about before. Most students were honest and forthright in their remarks. I preferred the small group discussion[s]; they allowed people to be more honest and open about their feelings. Hopefully [these sessions will] set a good tone/precedent for continuing dialogue during our time at Yale." 
From my own observations during the first part of the workshop, I was impressed by the amount of interaction and the thoughtfulness of first-year student responses. Students were remarkably thoughtful in their reactions during the panel discussion. Many students were eager to respond, sharing a wide range of thoughts and feelings related to the dilemmas raised in the cases.

The 22 upper-class students who facilitated the small group sessions believed that this had been a powerful learning experience for them, as well as for their group members. They confirmed that the first-year students seemed very pleased with an opportunity to talk about issues related to diversity and discrimination. The students were tremendously pleased with their efforts and plan to continue this orientation program as a student initiative next year.

The upper-class students also appreciated the opportunity to learn skills in group process during the facilitator workshop prior to the orientation session. The focus on listening and responding skills increased their confidence and comfort in working with students in the area of diversity. We expect to have the same workshop for our small group leaders next year.

\section{Discussion}

The message that diversity is an important concern at the Medical Center may best be conveyed by students. Even with the best intentions, presentations by faculty and staff can be perceived as preachy and patronizing. A moralizing tone can create even more resistance to thinking constructively about diversity. If the goal during orientation is to increase first-year students' comfort in thinking and talking about diversity, then it may be more helpful to have upper-class students facilitate this process.

Students who take responsibility for creating and implementing an educational program for their colleagues are likely to become empowered to speak out on issues that will confront them throughout their medical careers. As each of us learns to communicate our beliefs, thoughts, and feelings, we increase our understanding of commonalities as well as differences. As we begin to understand one another, we 
are more likely to create a collegial environment that promotes mutual trust and respect.

Faculty developers in educational institutions may be competent and skilled in working with faculty on the topic of diversity. It is natural that they offer support to students in designing the educational programs that will be most useful to their specific needs. Whether during orientation or on other occasions when requested by students, educational programs designed with and for students can be beneficial in promoting a greater understanding of and respect for diversity.

\section{References}

Beauvais, K. (1986). Workshops to combat sexual harassment: a case study of changing attitudes. Signs, 12, 130-145.

Cooper, J.E., \& Chattergy, V. (1993). Developing faculty multicultural awareness: An examination of life roles and their cultural components. To Improve the Academy, 12, 81-95.

Johnston, M. A. (1992, April). A model program to address insensitive behaviors toward medical students. Academic Medicine, 67(4), 236-237.

Mao, C., Bullock, C.S., Harway, E.C., \& Khalsa, S.K. (1988, August). A workshop on ethnic and cultural awareness for second-year students. Journal of Medical Education, 63, 624-628.

Thomann, D.A. (1989). An organizational development approach to preventing sexual harassment: Developing shared commitment through awareness training. CUPA Journal, 40, 34-43.

Wadsworth, E.C. (1992). Inclusive teaching: A workshop on cultural diversity. To Improve the Academy, 11, 233-240.

Wunsch, M.A. \& Chattergy, V. (1991). Managing diversity through faculty development. To Improve the Academy, 10, 141-150.

Yale Diversity Workshop Packet. (1993). (Available from [the Office of Educational Development, Yale University School of Medicine, 21 ESH, 367 Cedar Street, New Haven, CT 06510-8046]) 


\section{APPENDIX A Diversity Workshop Evaluation}

1. Please rate the overall effectiveness of the diversity workshop.

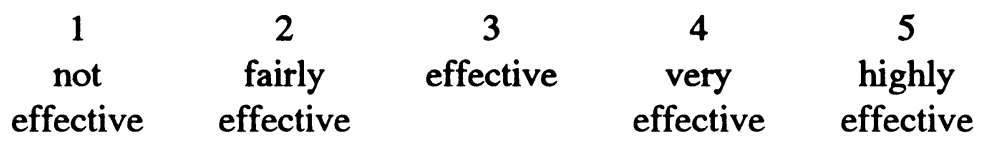

2. What did you like best about the workshop?

3. What were your impressions of:

Panel, large group activity?

Cases?

Small group?

Handouts?

4. What changes would you recommend for improving the workshop?

5. Would you like to participate in additional workshops throughout the year? 